\title{
Erratum to: Synthesis and Characterization of PVAc- $b$-PDMS- $b$-PVAc Triblock Copolymers by Atom Transfer Radical Polymerization Initiated by PDMS Macroinitiator
}

\author{
Mohammad Ali Semsarzadeh $\cdot$ Sahar Amiri
}

Published online: 19 January 2013

(C) Springer Science+Business Media New York 2013

Erratum to: J Inorg Organomet Polym

DOI 10.1007/s10904-012-9812-7

The original version of this article unfortunately contained two mistakes. The presentation of Scheme 3 and Fig. 5 was incorrect. The corrected Scheme 3 and Fig. 5 are given below.

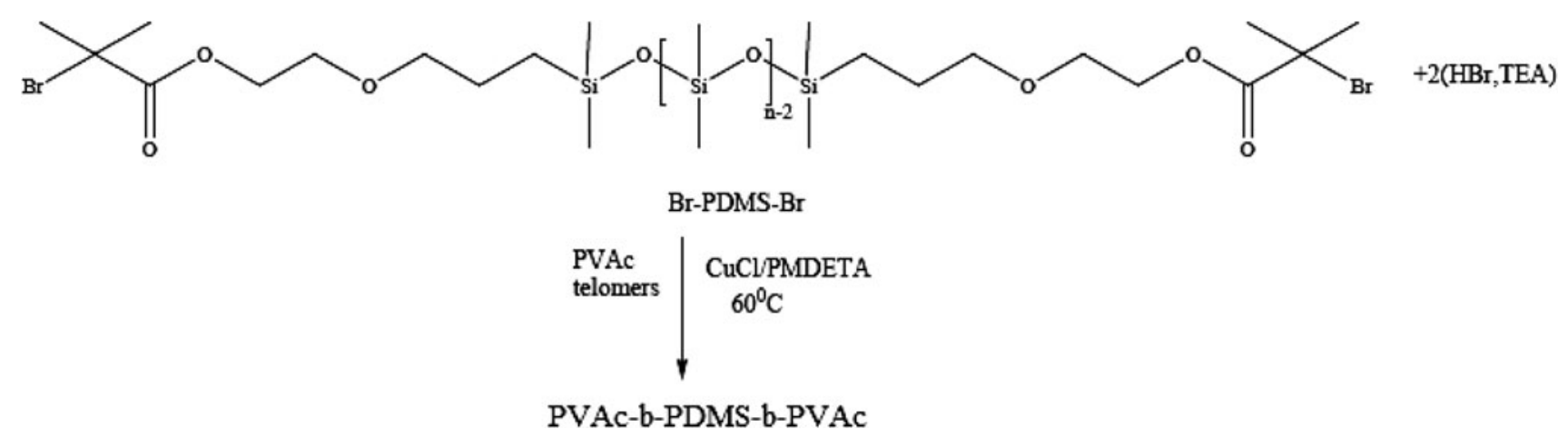

Scheme 3 ATRP route of PVAc telomers initiated with PDMS macroinitiators

The online version of the original article can be found under doi:10.1007/s10904-012-9812-7.

M. A. Semsarzadeh $(\bowtie) \cdot$ S. Amiri

Polymer Group, Chemical Engineering Department, Tarbiat

Modares University, P.O. Box 14155/143, Tehran, Iran

e-mail: semsarzadeh@modares.ac.ir 
Fig. $5{ }^{1} \mathrm{H}$ NMR spectrum for the ATRP of PDMS macroinitiator with PVAc telomers from a free radical telomerization, $\mathbf{b}$ controlled radical telomerization at $60{ }^{\circ} \mathrm{C}$ for $6 \mathrm{~h}$

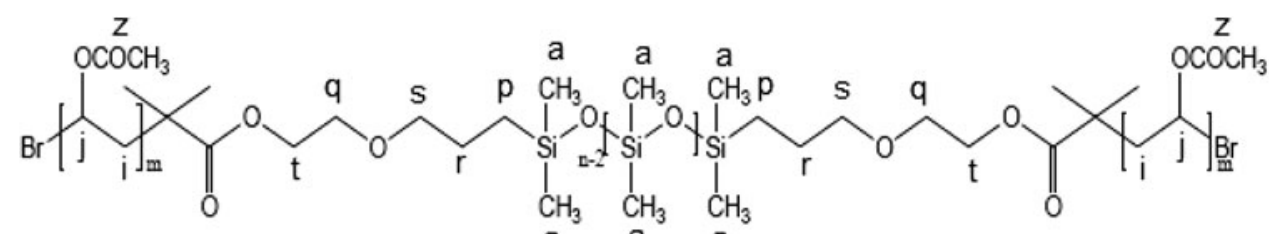

a a a

(b)

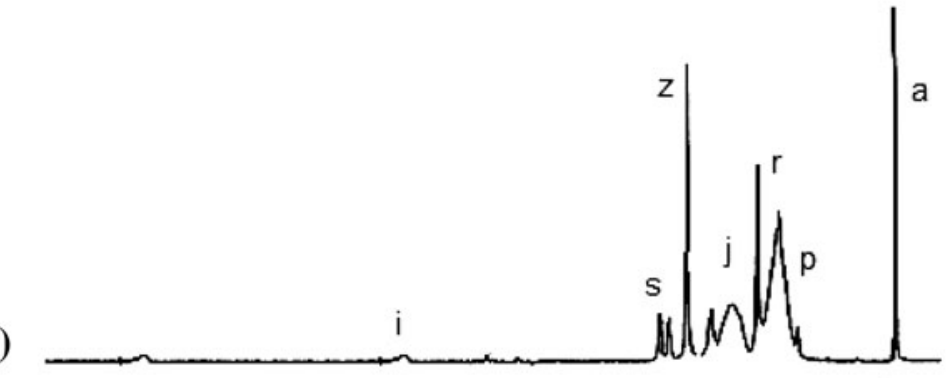

(a)

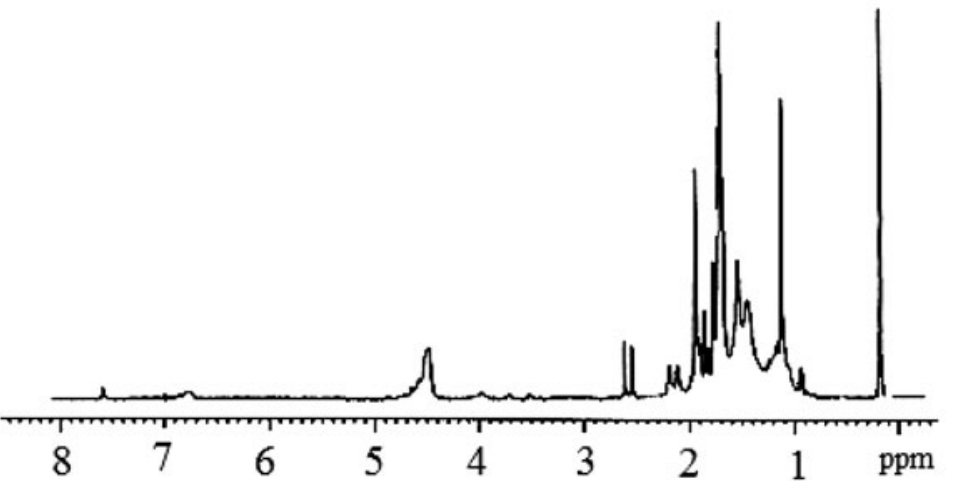

